\title{
Sedation for Gastrointestinal Endoscopy: Practical Issues in Patient Safety and Quality Management
}

\author{
Seung Bae Yoon and Young-Seok Cho \\ Division of Gastroenterology, Department of Internal Medicine, Seoul St. Mary's Hospital, College of Medicine, The Catholic University of \\ Korea, Seoul, Korea
}

See "Considerable Variability of Procedural Sedation and Analgesia Practices for Gastrointestinal Endoscopic Procedures in Europe" by Hermanus H. B. Vaessen and Johannes T. A. Knape, on page 47-55.

Due to the widespread use of screening endoscopy, the number of endoscopic procedures has increased considerably over the last decade. In recent years, advanced interventional endoscopic procedures, including endoscopic retrograde cholangiopancreatography, endoscopic ultrasonography, endoscopic submucosal dissection, and peroral endoscopic myotomy, has widely been adopted. Along with the development of lengthy and potentially uncomfortable endoscopic procedures, the rate of moderate to deep sedation has been increasing over the past few years. Sedation relieves patients' discomfort and anxiety, and consequently improves their toleration of and satisfaction with the procedure. Therefore, an adequate level of satisfactory endoscopic sedation makes endoscopic procedures safe and successful. Despite the benefits of sedation for gastrointestinal (GI) endoscopy, there are many hurdles to be overcome, including safety concerns, increasing medical costs, and quality management. Major scientific societies involved in GI endoscopy have developed curricula and guidelines based on several published studies showing that properly trained non-anesthesiologists and nurses may

Received: December 28, 2015 Accepted: December 31, 2015

Correspondence: Young-Seok Cho

Division of Gastroenterology, Department of Internal Medicine, Seoul St. Mary's Hospital, College of Medicine, The Catholic University of Korea, 222 Banpo-daero, Seocho-gu, Seoul 06591, Korea

Tel: +82-2-2258-6021, Fax: +82-2-2258-2038, E-mail: yscho@catholic.ac.kr

(c) This is an Open Access article distributed under the terms of the Creative Commons Attribution Non-Commercial License (http://creativecommons.org/ licenses/by-nc/3.0) which permits unrestricted non-commercial use, distribution, and reproduction in any medium, provided the original work is properly cited. effectively and safely manage sedation for endoscopic procedures. ${ }^{1-5}$ However, guidelines may differ among countries, depending on their healthcare systems and legal frameworks. ${ }^{6}$

Due to its benefits-such as rapid onset of action, improved patient comfort, and shorter recovery time-in several countries, there has been a tendency toward the use of propofol in sedation in place of the traditional administration of benzodiazepine, with or without opioids. ${ }^{5}$ In Korea, a study using National Health Insurance claims data reported that the number of patients who received propofol sedation for endoscopy has continuously increased from 2008 to 2012 . $^{7}$ Due to the limited availability of anesthesiologists, propofol sedation for endoscopic procedures is widely being performed by endoscopists or trained nurses. This practice is referred to as the non-anesthesiologist administration of propofol (NAAP). ${ }^{8}$ In 2010, the European Society of Gastrointestinal Endoscopy (ESGE), the European Society of Gastroenterology and Endoscopy Nurses and Associates, and the European Society of Anaesthesiology (ESA) formulated guidelines for NAAP for GI endoscopy. ${ }^{1}$ However, the ESA has officially and publicly dissociated itself from the NAAP guideline after the death of Michael Jackson as a result of propofol administration without appropriate monitoring. ${ }^{9}$ In Korea, public concern over the risk of propofol abuse has escalated following recent media reports of several cases of propofol abuse. ${ }^{7}$ Propofol was designated as a psychoactive drug on February 1, 2011. ${ }^{10}$ Although NAAP for GI endoscopy is used regularly in several countries, including Korea, its use is a matter of debate.

In this issue of Clinical Endoscopy, Vaessen and Knape ${ }^{11}$ 
present online survey reports on the status of procedural sedation and analgesia practices for GI endoscopy from 16 countries in Europe in 2012. The survey included questions about the type of sedation technique, the sedation practitioner, patient monitoring, training, informed consent and patient satisfaction, adherence to guidelines, and complication registration. The results showed a wide range of practices for moderate to deep sedation among and within European countries. Controlled sedation care (CSC) using propofol with or without opioids was administered predominantly in 8 countries, while traditional uncontrolled sedation care (USC), using benzodiazepines with or without opioids, was predominantly used in seven countries. This range may be due to the differences in medical systems and legislation among countries. With respect to the sedation practitioners, CSC was confined to anesthesiologists in only four countries (Bulgaria, Czech Republic, Luxembourg, and Portugal). In other countries, CSC was provided by various medical personnel, including endoscopists, endoscopic assistants, endoscopic nurses, nurse anesthetists, and other health care personnel. In the survey conducted by the Korean Society of Gastrointestinal Endoscopy (KSGE), 63\% of 1,332 survey respondents used propofol-based sedation, and the rate of endoscopist-directed propofol (EDP) sedation was $98.6 \% .^{12}$ In the present study by Vaessen and Knape, ${ }^{11}$ patient monitoring was abundantly applied in most countries, which potentially contributed to patient's safety. Pulse oximetry, heart rate, and non-invasive blood pressure were routinely monitored during CSC procedures in almost all countries, and electrocardiography and capnography were used in approximately half of the countries. Informed consent for sedation in both the USC group and CSC group was obtained in $65 \%$ of patients. In the current medical climate, negligent failure to inform the patient is usually regarded as a liability claim against a doctor. The ESGE guidelines suggest that informed consent should be obtained from the patient prior to the procedure. ${ }^{1,5}$

In the present survey, the rate of respondents to indicate adherence to international or domestic guidelines for moderate to deep sedation was low (25\%), and the rate of the responsible sedationists taking skills training programs was also unsatisfactory. In the Korean survey, 8.9\% of all respondents had not any training for sedation practices, and $45 \%$ of respondents indicated that periodic retraining on basic life support was not enforced for all medical personnel involved in sedation practices. ${ }^{12}$ Untrained sedation practitioners may not be familiar with, and may not properly respond to unavoidable adverse effects of sedative drugs. A previous study showed that proper training for non-anesthesiologist sedation practitioners could significantly lower sedation-related complications during endoscopic procedures. ${ }^{13}$ Academic societies of endoscopy should develop appropriate training programs for sedation for GI endoscopy, which would include courses on basic life support, advanced cardiovascular life support, basic airway management, treatment of respiratory problems, sedation theoretical and practical courses. These societies would also encourage the completion of specialized training programs. Although the survey by Vaessen and Knape ${ }^{11}$ showed considerable differences in the practice of sedation in many European countries and the importance of its quality control, the study has limitation which data from gastroenterologists were not included. Furthermore, online surveys may not reflect the real field of sedation practices in respect to quality and safety. A future survey is necessary to include the perspectives of both the sedation practitioners and patients.

A recent study, using the Korean Society of Anesthesiologists database of anesthesia-related medical disputes from July 2009 to June 2014, analyzed 105 surgical anesthesia cases. ${ }^{14}$ In this study, cases related to general anesthesia were the most common (50 cases, $48 \%$ ), followed by sedation cases (39 cases, $37 \%)$. Propofol-based sedation was used in $90 \%$ of sedation cases. Most sedation cases (69\%) showed deviations from the appropriate standard of care (i.e., determined to be avoidable), including no pre-procedural testing, no pre-anesthetic records or anesthesia records, no intraoperative monitoring, and no oxygen supplementation. In addition, most sedation (92\%) was provided simultaneously by non-anesthesiologists performing the surgical/diagnostic procedure. Further studies including the incidence of sedation-related adverse events during GI endoscopy in Korea are necessary. Currently, the Korean Medical Association is developing guidelines for propofol sedation in primary care practices and emphasizes sedation practices under supervision by trained practitioner. In 2015, the KSGE published, "A guidebook on sedation for gastrointestinal endoscopy." Several studies worldwide demonstrated that EDP sedation is a safe procedure. ${ }^{15}$ Considering that EDP sedation will be increasingly used in Korea, the KSGE should make every effort in conjunction with other sedation-related societies to develop programs for quality management, anesthesiologist assistance guidelines, and other training programs (training in management of complications, airway workshop, simulation training, etc.).

Conflicts of Interest

The authors have no financial conflicts of interest.

\section{REFERENCES}

1. Dumonceau JM, Riphaus A, Aparicio JR, et al. European Society of Gastrointestinal Endoscopy, European Society of Gastroenterology and Endoscopy Nurses and Associates, and the European Society of Anaesthesiology guideline: non-anesthesiologist administration of propofol 
for GI endoscopy. Endoscopy 2010;42:960-974.

2. American Association for Study of Liver Diseases; American College of Gastroenterology; American Gastroenterological Association Institute, et al. Multisociety sedation curriculum for gastrointestinal endoscopy. Gastrointest Endosc 2012;76:e1-e25.

3. Dumonceau JM, Riphaus A, Beilenhoff U, et al. European curriculum for sedation training in gastrointestinal endoscopy: position statement of the European Society of Gastrointestinal Endoscopy (ESGE) and European Society of Gastroenterology and Endoscopy Nurses and Associates (ESGENA). Endoscopy 2013;45:496-504.

4. ASGE Ensuring Safety in the Gastrointestinal Endoscopy Unit Task Force, Calderwood AH, Chapman FJ, et al. Guidelines for safety in the gastrointestinal endoscopy unit. Gastrointest Endosc 2014;79:363-372.

5. Dumonceau JM, Riphaus A, Schreiber F, et al. Non-anesthesiologist administration of propofol for gastrointestinal endoscopy: European Society of Gastrointestinal Endoscopy, European Society of Gastroenterology and Endoscopy Nurses and Associates guideline: updated June 2015. Endoscopy 2015;47:1175-1189.

6. Lee TH, Lee CK. Endoscopic sedation: from training to performance. Clin Endosc 2014;47:141-150.

7. Shin JY, Lee SH, Shin SM, Kim MH, Park SG, Park BJ. Prescribing patterns of the four most commonly used sedatives in endoscopic examination in Korea: propofol, midazolam, diazepam, and lorazepam. Regul Toxicol Pharmacol 2015;71:565-570.

8. Rex DK, Deenadayalu VP, Eid E, et al. Endoscopist-directed adminis- tration of propofol: a worldwide safety experience. Gastroenterology 2009;137:1229-1237.

9. Perel A. Non-anaesthesiologists should not be allowed to administer propofol for procedural sedation: a Consensus Statement of 21 European National Societies of Anaesthesia. Eur J Anaesthesiol 2011;28:580584 .

10. Kim JH, Byun H, Kim JH. Abuse potential of propofol used for sedation in gastric endoscopy and its correlation with subject characteristics. Korean J Anesthesiol 2013;65:403-409.

11. Vaessen HH, Knape JT. Considerable variability of procedural sedation and analgesia practices for gastrointestinal endoscopic procedures in Europe. Clin Endosc 2016;49:47-55.

12. Lee CK, Dong SH, Kim ES, et al. Room for quality improvement in endoscopist-directed sedation: results from the first nationwide survey in Korea. Gut Kiver 2016;10:83-94

13. Patel S, Vargo JJ, Khandwala F, et al. Deep sedation occurs frequently during elective endoscopy with meperidine and midazolam. Am J Gastroenterol 2005;100:2689-2695.

14. Roh WS, Kim DK, Jeon YH, et al. Analysis of anesthesia-related medical disputes in the 2009-2014 period using the Korean Society of Anesthesiologists database. J Korean Med Sci 2015;30:207-213.

15. Sieg A; bng-Study-Group, Beck S, et al. Safety analysis of endoscopist-directed propofol sedation: a prospective, national multicenter study of 24441 patients in German outpatient practices. J Gastroenterol Hepatol 2014;29:517-523. 